\title{
Embracing the challenge
}

\author{
Orthodontic dental nurses are going from strength to strength, \\ says Fiona Grist, Vice Chairman of the Orthodontic National Group.
}

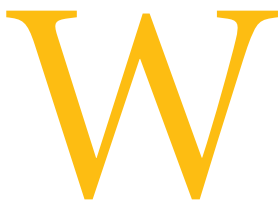

ith many orthodontic dental nurses already in the registration process with the General Dental Council (GDC), and many more about to submit their applications, orthodontic dental nursing is achieving another milestone.

When the Orthodontic National Group for Dental Nurses (ONG) was set up in 1994, its ultimate goal was to create career pathways for dental nurses. This would provide them with ongoing professional development, extended duties and recognition as professionals complementary to dentistry (PCDs). A lot has happened in the intervening 13 years and plans to achieve even more are being driven forward by the enthusiasm of the ONG's members.

\section{Raising standards}

The first step taken by the ONG was to act on behalf of all orthodontic dental nurses to raise standards by developing their roles. In 2005 this was amended to orthodontic dental

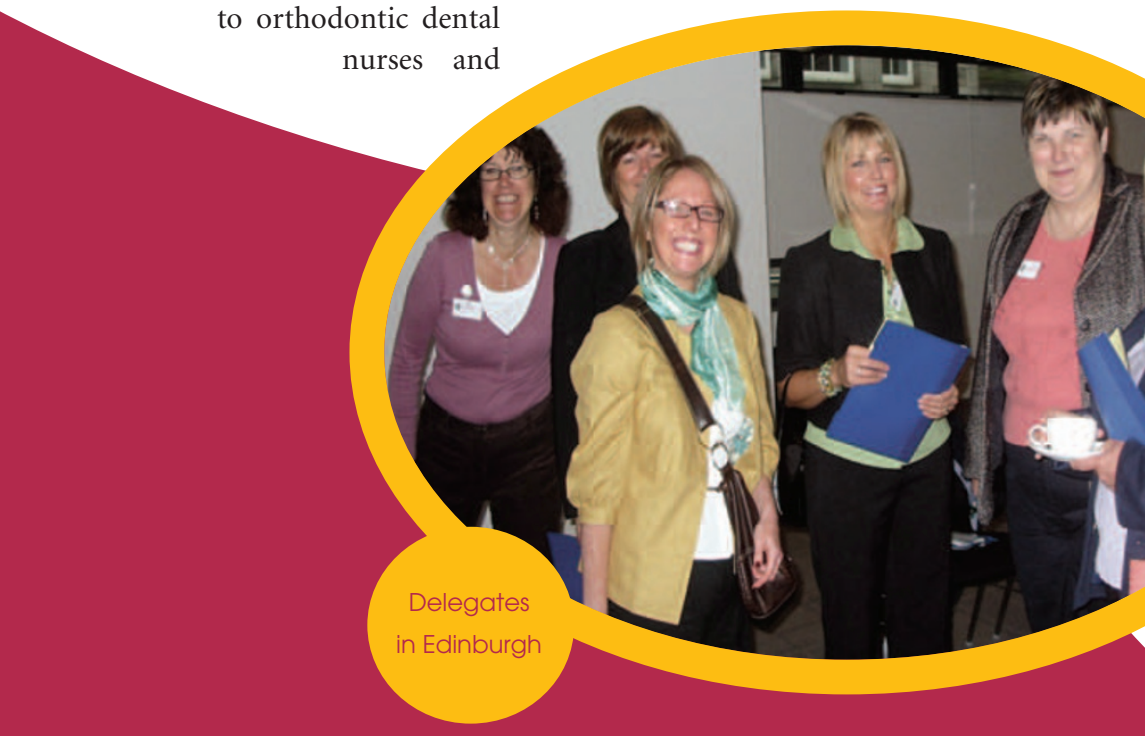

therapists under the new umbrella title of 'dental care professional' (DCP). This year courses for orthodontic therapists are finally coming on stream at Leeds and Bristol and possibly Cardiff and Manchester.

It is due in part to direct representation to the GDC that the term 'orthodontic therapist' was accepted. The curriculum was developed by a GDC Working Party in collaboration with ONG and the British Orthodontic Society. There is now an established post-qualification for dental nurses, the Certificate in Orthodontic Nursing.

\section{Ongoing development}

ONG provides ongoing professional development by organising at least two study days a year. These are all day meetings, open to all orthodontic nurses, with the emphasis on clinical lectures. The ONG issues a quarterly journal which keeps the membership informed of meetings, events, comings and goings and happenings within orthodontics. Clinical articles contain a wide range of topics designed to enhance knowledge and stimulate interest in new techniques and methods of treatment.

The ONG became an affiliated organisation of the British Orthodontic Society (BOS) in 1997 and appreciates the support it receives from them and the profession. This year marks the centenary of the founding of the first orthodontic society, the British Society for the Study of Orthodontics (BSSO). After the BSSO were founded in 1907, several other societies formed until eventually they all united in 1994 and became the British Orthodontic Society we know today. Even though orthodontics was already well established in 1907, the last century has seen amazing developments and innovation.

\section{Annual events}

Every September nurses are invited to attend the British Orthodontic Conference as part of the orthodontic team. A Nurses Day is organised by the ONG and held in a separate auditorium. Nurses are encouraged to go to other lectures on the main programme and to take advantage of the large trade exhibition too.

ONG organises two dental nurse competitions annually with the help of sponsors. On the Nurses Day at Conference the five finalists of the Orthodontic Dental Nurse of the Year Award make a ten minute presentation. This is judged by an expert panel and the results announced at the end of the day, along with the winners of the Orthodontic Dental Nurse Prize, awarded for the best presentation folder.

In 2005, the British Orthodontic Society was a supporting organisation of the $6^{\text {th }}$ International Orthodontic 


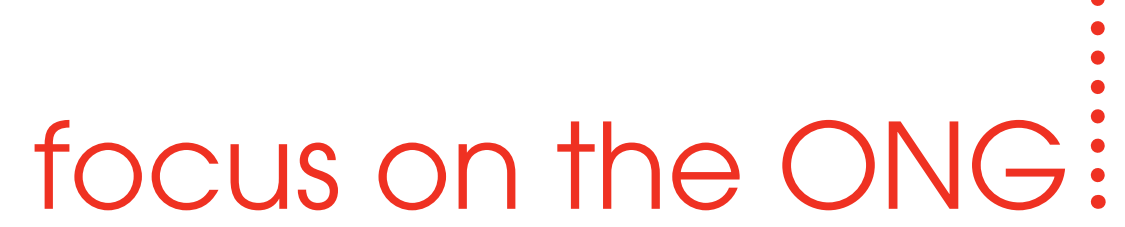

Congress held in Paris. Over 900 dental nurses and assistants attended from many countries, over a third of them from the UK and Ireland, and the Nurse of the Year Award was replaced on the occasion by the World Orthodontic Nurse Award.

Recently ONG was represented at the British Dental Conference and Exhibition held in Harrogate in May and nurses also attended the BOS Meetings in London and York. A successful study day was held in Bristol in March, and the study day in Edinburgh in June included a well illustrated presentation on the use of mini screw implants, a guided tour of orthognathic surgery, and a lively talk on orthodontics from a retail perspective.

At this particular event Janet Robins, Chief Executive Officer of ONG, was able to update everyone on the very latest developments on statutory registration, $\mathrm{CPD}$, training opportunities and courses.

\section{The future}

From 2008, members for the DCP groups, including ONG, have been asked to sit on GDC committees covering a wide range of areas such as education, fitness to practise, standards, registration and scope of practice.

As continuing professional development (CPD) regulations come into play, 'points' allocated to the study days and courses nurses attend will be added to their tally of verifiable CPD. Orthodontists are very supportive of the new requirements and actively encourage their staff to expand their knowledge, and it is good to see that study days are already well attended.

The British Orthodontic Conference this year is in September and orthodontic nurses all over the country plan to be there. Not only is it a chance to attend a full and interesting lecture programme but it is also good to meet old friends and make new ones. ONG has a Nurses' Meal to which

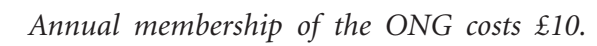
See www.orthodontic-ong.co.uk or telephone 01723342113 for more information.

\section{Exciting times}

ONG provides focus, assistance and guidance for members. It is managed by a small and efficient committee of working orthodontic nurses who experience many of their colleagues' problems and concerns at grass roots - very much professional dental nurses working on behalf of dental nurses. The future looks full of promise and challenges for everyone on an almost unparalleled scale. Many of the objectives set out back in 1994 have been achieved; statutory registration is under way, the Certificate in Orthodontic Dental Nursing is well established and more centres are enrolling on the orthodontic therapist courses. As DCPs, nurses are invited to sit on committees which regulate and advise in many areas. There is even the possibility of these DCPs becoming practice owners, employing the clinicians! These are exciting times; career pathways are opening up and fresh opportunities abound like never before. There are still goals to work towards, but orthodontic dental nurses are all set to continue embracing the challenge!

作 